whether any changes are sustained. The current study formed part of a European-based educational programme that was implemented in a low-income South African context to help improve adolescents' attitudes and knowledge about injuries.

Aim To assess changes in grade 11 high school learners' injury prevention knowledge and attitudes, after exposure to a comprehensive educational programme on the European Code Against Injuries (ECAI).

Methods A randomised pre-test and post-test design was used to evaluate the outcome of an injury prevention educational programme shown to grade 11 adolescents living in a low-income community in South Africa. There were 56 participants in the control and 57 participants received the intervention. Pre- and postlevel assessment took place before and after the intervention. The instrument covered knowledge and attitudes associated with selfreported potentially harmful and protective behaviours with regards to injury. Both descriptive and bi-variate analysis was undertaken.

Results Adolescents that received the ECAI programme did show some improvements in knowledge when pre- and post-measures were compared, however, it was found not to be statistically significant.

Significance to the Field These findings suggest that the multimedia approach did not significantly improve adolescents' knowledge and attitudes about injuries. Future studies should consider a contextually congruent curriculum that examines injury prevention within low-income settings. Reinforcement of these injury prevention messages at regular intervals may contribute to a significant shift in learners' knowledge and attitude about safety promotion.

\section{THE EFFECTIVENESS OF A SCHOOL-BASED EUROPEAN INJURY PREVENTION PROGRAMIME ON ADOLESCENT RISK BEHAVIOUR IN A SOUTH AFRICAN SETTING}

doi:10.1136/injuryprev-2012-040590d.29

${ }^{1}$ Arendse Najuwa, ${ }^{1}$ Bulbulia Samed, ${ }^{2}$ van Niekerk Ashley, ${ }^{1}$ Mohamed Seedat. ${ }^{1}$ Institute for Social and Health Sciences, University of South Africa; ${ }^{2}$ Safety and Peace Promotion Research Unit (SAPPRU), Medical Research Council-University of South Africa

Background Unintentional injuries are identified as a major health concern among adolescents. The one factor that can contribute significantly to their increased rates of injury is their risk taking behaviour. Evidence shows that certain education based strategies in schools can promote safer behaviours, though it is unclear 